\title{
NUMERICAL ASPECTS OF THE SECONDARY MAGNETIC FIELD MAPPING IN MAGNETIC INDUCTION TOMOGRAPHY
}

\author{
Beata Szuflitowska, Marcin Ziolkowski, Krzysztof Stawicki \\ West Pomeranian University of Technology, Szczecin
}

Abstract. Magnetic Induction Tomography (MIT) belongs to the noncontact electromagnetic imaging techniques. This paper focuses on determination of a secondary magnetic field map calculated with the help of the Biot-Savart law around the low-conductivity object. The inclusions of various shapes and different electrical conductivities values and two measurement planes are considered. In each case the objects' single maximal cell volume with assumed uniform eddy current density has been determined. In order to keep the relative error below $1 \%$ the object should be divided in most cases into elements with maximal cell volume equal to $0.244 \mathrm{~mm}^{3}$ for $y z$ - plane, and $0.03 \mathrm{~mm}^{3}$ for $x y$ - plane.

Keywords: magnetic induction tomography, eddy currents, forward problem, electrical conductivity

\section{NUMERYCZNE ASPEKTY ODWZOROWANIA WTÓRNEGO POLA MAGNETYCZNEGO W MAGNETYCZNEJ TOMOGRAFII INDUKCYJNEJ}

Streszczenie. Magnetyczna Tomografia Indukcyjna (MIT) należy do bezkontaktowych, elektromagnetycznych technik obrazowania. Artykut skupia się na wyznaczeniu mapy wtórnego pola magnetycznego obliczonego za pomoca prawa Biota-Savarta wokót obiektu staboprzewodzącego. Przeanalizowano wtracenia o różnym kształcie i różnej wartości konduktywności elektrycznej oraz dwie płaszczyzny pomiarowe. W każdym przypadku została wyznaczona maksymalna objętość pojedynczej komórki obiektu z założona stała wartościa gestości prądu. W celu uzyskania błędu względnego poniżej 1\% obiekt powinien zostać podzielony $w$ większości przypadków na elementy z maksymalna objętościa równa $0,244 \mathrm{~mm}^{3}$ dla płaszczyzny yz oraz 0,03 mm dla plaszczyzny $x y$.

Słowa kluczowe: magnetyczna tomografia indukcyjna, prądy wirowe, zagadnienie proste, konduktywność elektryczna

\section{Introduction}

Magnetic Induction Tomography (MIT) belongs to the noncontact electromagnetic imaging techniques. The purpose of these methods is a determination of electrical conductivity and permittivity distribution inside the object under test. However, most studies to date have concentrated on imaging the conductivity. In case of low-conductivity objects the MIT system must be designed very carefully, and in order to assure the highest MIT resolution, further research needs to be continued [1, 3].

MIT setup can be configured in many different ways. Typically, it operates by injecting a primary time-varying magnetic field, generated by an exciter (a single coil or a given spatial arrangement of coils), into the object being tested. This magnetic field induces eddy currents in the object which in turn produce a secondary magnetic field sensed by an array of detecting coils placed near the conductive body surface. The secondary magnetic field contains information about the spatial distribution in the region of interest of the electrical conductivity.

The MIT system which has been developed at the West Pomeranian University of Technology, Szczecin, Poland consists of one exciter (schematically shown in Fig. 1) and receivers. The excitation unit uses a coil, ferromagnetic core and conducting shield. The magnetically permeable core, located at the centre of the screen, is capable of concentrating the primary magnetic field lines and can increase the magnetic field intensity of the coil. The aim of the conducting shield is to protect the primary magnetic field from scatter and to concentrate it in a given region in the testing object [5-7].

In simulations, the modeling of MIT process involves two main parts. First, the so-called forward problem is calculated, which consists of two steps. At the beginning, the eddy current density distribution inside the object under test is calculated. Next, the process of the secondary magnetic flux density vector determination takes place. The proper evaluation of the secondary magnetic field is essential in order to solve the second, final part (called the inverse problem) of the whole MIT procedure [3, 4].

In [6] the fast calculation procedure allowing the determination of the eddy current density distribution for the complex 3D geometries has been provided. The current paper is a continuation of the previous research and treats in a quantitative way the possibility of the secondary magnetic field calculations from an assumed discretization level of the object under test with low-conductivity inclusions. In this article we analyse various objects' types, different inclusions with various electrical conductivities' values and two measurement planes. In all cases the objects' maximal cell volume with assumed uniform eddy current density have been determined.

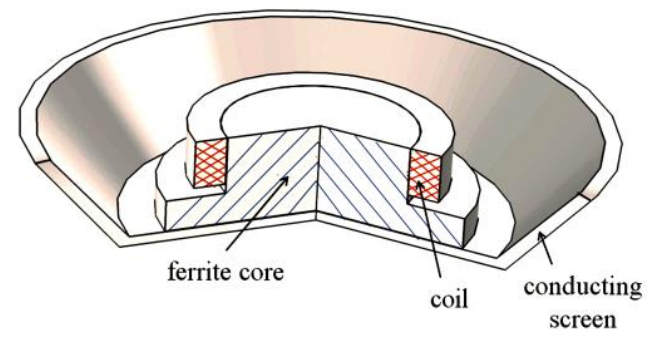

Fig. 1. The exciter scheme developed at the West Pomeranian University Technology

\section{Methodology}

The MIT forward problem is a classical eddy current problem, which can be analysed using Maxwell's equations. The electric field $\boldsymbol{E}$ inside the object can be expressed as [1]:

$$
\boldsymbol{E}=-j \omega \boldsymbol{A}-\nabla \boldsymbol{\Phi}
$$

where: $\omega$ - radial frequency, $\boldsymbol{A}$ - the magnetic vector potential, $\Phi-$ the electric scalar potential.

The continuity equation inside the low-conductivity object, under the assumption that the displacement current is negligible compared to the conduction current can be written as [1]:

$$
\nabla \cdot(\sigma \nabla \Phi)=-j \omega \boldsymbol{A} \cdot \nabla \sigma
$$

where: $\sigma$-electrical conductivity.

Assuming that the real part of the electric scalar potential is equal to zero and the secondary field does not change the primary field, equation (2) can be rewritten as:

$$
\nabla \cdot\left(\sigma \nabla \Phi_{i}\right)=-j \omega \boldsymbol{A}_{p} \cdot \nabla \sigma
$$

where: $\Phi_{i}$ is the imaginary part of the electric scalar potential, $\boldsymbol{A}_{p}$ - the primary magnetic vector potential.

The current continuity condition for two different media of conductivities $\sigma_{1}$ and $\sigma_{2}$ can be expressed as:

$$
\sigma_{1}\left(\frac{\partial \Phi_{1 i}}{\partial n}+\omega A_{p 1 n}\right)=\sigma_{2}\left(\frac{\partial \Phi_{2 i}}{\partial n}+\omega A_{p 2 n}\right)
$$

where: $A_{p n}$ is the normal component of the primary magnetic vector potential and $n$ - the normal direction $[2,3,7]$. 
If $\sigma_{2}=0$ one can obtain the boundary condition on the object boundary:

$$
\frac{\partial \Phi_{i}}{\partial n}=-\omega A_{p n}
$$

The induced current density in the conductive object is calculated using the Ohm's law:

$$
\boldsymbol{J}=\sigma \boldsymbol{E}=-j \sigma\left(\omega \boldsymbol{A}_{p}+\nabla \boldsymbol{\Phi}_{i}\right)
$$

Figure 2 shows an exemplary discretized object with assumed uniform current density $\boldsymbol{J}^{(e)}$ in each cell (i.e. element in the shape of rectangular prism). It is stated that in the first case magnetic field measurement points are in $y z$-plane (grid consists of $21 \times 21$ points), which is located on the opposite side of the object than the excitation unit. In the second case magnetic field measurement points are in $x y$ - plane (here grid consists of $11 \times 11$ points) and is located over the testing object.

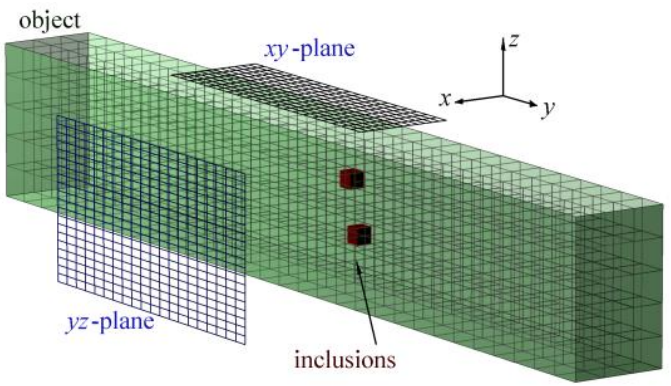

Fig. 2. The exemplary discretized object (discretization: 3 - in the direction of the $x$ axis, 30 - in y axis, 5 - in z axis) with inclusions into total 450 elements in the shape of rectangular prisms with assumed uniform current density

The simulations have been carried out with COMSOL Multiphysics 5.1 and Matlab. The magnetic field of the exciter is computed in the axisymmetric finite element model (using Magnetic Field Module). In this case only one, angular component of magnetic vector potential exists, i.e. $\boldsymbol{A}=A_{\varphi}(r, z) \mathbf{1}_{\varphi}$. The values of $A_{\varphi}$ are converted into $A_{y}$ and $A_{z}$ in three dimensional Cartesian coordinate system. The boundary conditions at the edges of the object and inclusions are calculated based on the values of the primary magnetic field, parameters of the object and inclusions (conductivities, positions and shapes). Next, these boundary conditions are applied in the 3D finite element model, which contains the object with inclusions inside. Using electrostatic potential formula in Comsol Electrostatic Module one can apply the extra fine mesh and compute more accurately induced eddy currents [6].

Exemplary induced eddy current lines in the central part of the object with two different inclusions are shown in Fig. 3. The conductivity of the object is equal to $0.115 \mathrm{~S} / \mathrm{m}$, conductivity of the upper and lower inclusion equal to $0.0625 \mathrm{~S} / \mathrm{m}$ and $1 \mathrm{~S} / \mathrm{m}$, respectively.

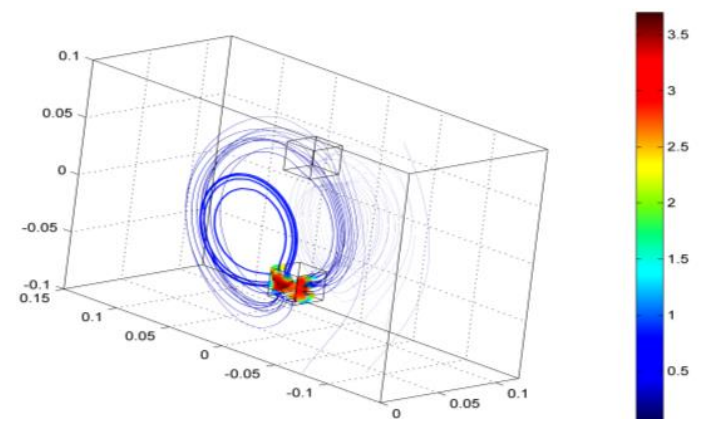

Fig. 3. Exemplary induced eddy current lines in the central part of the object $\left(A / \mathrm{m}^{2}\right)$

Figures 4-5 present absolute values of the eddy current density induced in the object with an inclusion of complex shape in the $y z$ -plane. The conductivity of the object presented in Fig. 4 is equal to $0.15 \mathrm{~S} / \mathrm{m}$, while the conductivity of the inclusion $-0.01 \mathrm{~S} / \mathrm{m}$. The slice intersects the middle of the inclusion. It can be see that the currents flow around the inclusion. The conductivity of the inclusion from the Fig. 5 is six times higher than the conductivity of the object. The colors are marked on the surface model. The right corner on the figure shows induced eddy currents on the slice through the inclusion.

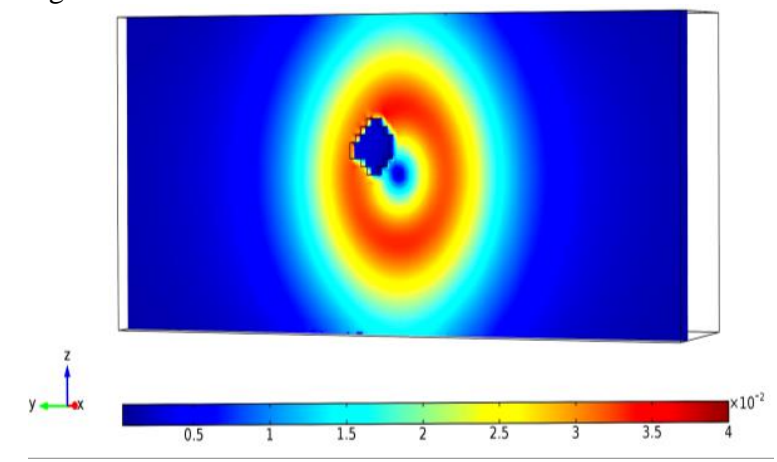

Fig. 4. Absolute value of eddy current density $\left(\mathrm{A} / \mathrm{m}^{2}\right)$ induced in the object $(\sigma=0.15$ $\mathrm{S} / \mathrm{m})$ with an inclusion $(\sigma=0.75 \mathrm{~S} / \mathrm{m})$ of complex shape

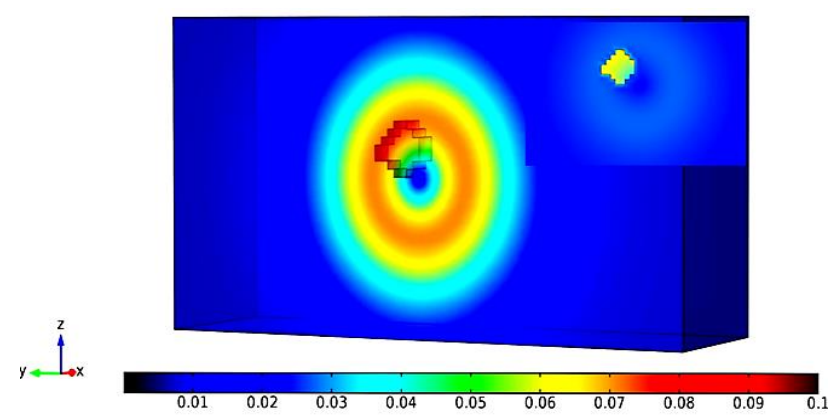

Fig. 5. Absolute value of eddy current density $\left(\mathrm{A} / \mathrm{m}^{2}\right)$ induced in the object $(0.15 \mathrm{~S} / \mathrm{m})$ with an inclusion $(0.75 \mathrm{~S} / \mathrm{m})$

The second step of the MIT forward problem requires applying the Biot-Savart law, which in discrete form can be written as follows [7]:

$$
\boldsymbol{B}\left(r_{m}\right)=\frac{\mu_{0}}{4 \pi} \sum_{e} \frac{\boldsymbol{J}^{(e)}\left(r^{\prime}\right) \times\left(r_{m}-r^{\prime}\right)}{\left|r_{m}-r^{\prime}\right|^{3}} \Delta V^{\prime}
$$

where: $r_{m}=[x, y, z]-$ position vector for the measurement point, $r^{\prime}=\left[x^{\prime}, y^{\prime}, z^{\prime}\right]-$ position vector for the source point, $\Delta V^{\prime}$ is the volume of the individual element in the shape of rectangular prism with uniform current density distribution $\boldsymbol{J}^{(e)}, \boldsymbol{B}$ - magnetic flux density vector. To simplify the notation we can assume:

$$
\begin{gathered}
r_{x}=x-x^{\prime}, r_{y}=y-y^{\prime}, r_{z}=z-z^{\prime} \\
r=\sqrt{r_{x}^{2}+r_{y}^{2}+r_{z}^{2}} \quad \rho_{x}=\frac{r_{x}}{r^{3}}, \rho_{y}=\frac{r_{y}}{r^{3}}, \rho_{z}=\frac{r_{z}}{r^{3}}
\end{gathered}
$$

At any $i$-point the value of the magnetic flux density depends on the current distribution in whole object consisting of elements that have an equal volume $d V^{\prime}$. Therefore, values of the magnetic flux density components (derived from each $j$-element) are summed up:

$$
\begin{aligned}
& B_{x, i}=10^{-7} d V^{\prime}\left(\sum_{j} J_{y, j} \rho_{z, i-j}-\sum_{j} J_{z, j} \rho_{y, i-j}\right) \\
& B_{y, i}=10^{-7} d V^{\prime}\left(\sum_{j} J_{z, j} \rho_{x, i-j}-\sum_{j} J_{x, j} \rho_{z, i-j}\right) \\
& B_{z, i}=10^{-7} d V^{\prime}\left(\sum_{j} J_{x, j} \rho_{y, i-j}-\sum_{j} J_{y, j} \rho_{x, i-j}\right)
\end{aligned}
$$

The above mentioned system of expressions can be rewritten in a matrix form as follows:

$$
\boldsymbol{R} \boldsymbol{J}=\boldsymbol{B}
$$

where: $\boldsymbol{B}$ is an $m \times 1$ matrix of "measurements" (three components of the magnetic flux density vector in each measurement point), $\boldsymbol{J}$ is $n \times 1$ matrix of current densities (three components of the eddy current density vector in each rectangular prism) and $\boldsymbol{R}$ is an $m \times n$ "distance" matrix [7]. 
In Magnetic Induction Tomography the proper determination of the secondary magnetic field map is crucial for the image reconstruction effectiveness. Generally, the object's discretization level is unknown, and in order to precisely determine the maximal dimensions of the individual rectangular prism (under the satisfied condition of the uniform current density distribution in each object's element) a special quality indicator must be introduced. The relative error $\delta_{j}(\%)$, calculated separately for three magnetic flux density vector components, can be determined by the following expression:

$$
\delta_{j}(\%)=\frac{\left|\sqrt{\sum_{i=1}^{p} B_{i j}^{2}(k)}-\sqrt{\sum_{i=1}^{p} B_{i j}^{2}(k-1)}\right|}{\sqrt{\sum_{i=1}^{p} B_{i j}^{2}(k)}} \cdot 100 \%
$$

where: $p=$ is the maximum number of measurement points, $k=2$, 3,4 - is the discretization level's number, which corresponds to the object's discretization level, $j=x$ either $y$, or $z$ (depending on the magnetic field component).

\section{Numerical results}

The validity of the stated in previous section assumptions has been examined using several examples. In calculations it is assumed, that the geometrical dimensions of the object are 12 $\mathrm{cm} \times 120 \mathrm{~cm} \times 20 \mathrm{~cm}$ in $x, y$ and $z$ axis, respectively. The exciter with the rms current $I=120 \mathrm{~mA}$ is placed in the centre of the rectangular co-ordinate system. In all simulations the current frequency in the excitation unit is equal to $35 \mathrm{kHz}$. For each discretization number $k$ (it corresponds to the object's discretization level) the values of relative error $\delta_{j}$ have been calculated. In the initial discretization $(k=1)$ the object has been divided into total 28800 rectangular prisms, i.e. 12 - in the direction of the $x$ axis, 120 - in the direction of the $y$ axis and 20 - in the direction of the $z$ axis. In each consecutive discretization's level $(k>1)$ the number of elements in each direction has been doubled. The process of increasing the elements' number (increasing the discretization's level) has been repeated up until the relative error $\delta_{j}$ value below $1 \%$ has been achieved. Table 1 presents the total number of elements and volume value of individual element for each discretization level's number $k$.

Table 1. The total number of elements, volume of single element for each discretization level's number $k$

\begin{tabular}{|c|c|c|c|}
\hline$k$ & $\begin{array}{c}\text { Volume } \\
\text { of rectangular } \\
\text { prims }\left[\mathrm{mm}^{3}\right]\end{array}$ & $\begin{array}{c}\text { Discretization in the } \\
\text { direction of the } x, y \text { and } z \\
\text { axis, respectively }\end{array}$ & $\begin{array}{c}\text { Total number of } \\
\text { rectangular prisms }\end{array}$ \\
\hline 1 & 1000 & $12 \times 120 \times 20$ & 28800 \\
\hline 2 & 125 & $24 \times 240 \times 40$ & 230400 \\
\hline 3 & 15.625 & $48 \times 480 \times 80$ & 1843200 \\
\hline 4 & 1.950 & $96 \times 960 \times 160$ & 14745600 \\
\hline 5 & 0.244 & $192 \times 1920 \times 320$ & 117964800 \\
\hline 6 & 0.03 & $384 \times 3840 \times 640$ & 943718400 \\
\hline
\end{tabular}

The first simulation was carried out for the homogeneous model (without inclusions). The electrical conductivity of the object was set to $0.115 \mathrm{~S} / \mathrm{m}$. Table 2 presents the values of the relative error $\delta_{j}$ as a function of the discretization level's number $k$, calculated for two measurement planes: $y z$ and $x y$, respectively.

Table 2. The values of the relative error $\delta_{i}$ as a function of the discretization level's number $k$ for homogeneous object

\begin{tabular}{|c|c|c|c|c|c|c|}
\hline \multirow{2}{*}{$k$} & \multicolumn{3}{|c|}{$y z-$ plane } & \multicolumn{3}{c|}{$x y-$ plane } \\
\cline { 2 - 7 } & $\delta_{x}(\%)$ & $\delta_{y}(\%)$ & $\delta_{z}(\%)$ & $\delta_{x}(\%)$ & $\delta_{y}(\%)$ & $\delta_{z}(\%)$ \\
\hline 2 & 3.900 & 4.200 & 3.900 & 6.74 & 5.44 & 4.82 \\
\hline 3 & 2.160 & 1.890 & 1.500 & 3.930 & 2.991 & 3.030 \\
\hline 4 & 1.116 & 1.100 & 0.900 & 1.811 & 1.562 & 1.551 \\
\hline 5 & $\mathbf{0 . 6 3 0}$ & $\mathbf{0 . 4 8 0}$ & $\mathbf{0 . 3 9 0}$ & 1.051 & 0.678 & 0.664 \\
\hline 6 & - & - & - & $\mathbf{0 . 5 8 6}$ & $\mathbf{0 . 3 3 4}$ & $\mathbf{0 . 3 2 8}$ \\
\hline
\end{tabular}

Next, calculations have been performed for the object with two different inclusions (Fig. 3) of conductivities equal to 0.0625 $\mathrm{S} / \mathrm{m}$ (upper one) and $1 \mathrm{~S} / \mathrm{m}$ (lower one). The differences in the values of the conductivities are similar to brain structure (the conductivity of the grey matter is about 1.5 times higher than white matter and conductivities of some pathologies, i.e. brain hematomas are 10 times higher than healthy tissues) [8]. Table 3 presents relevant results.

Table 3. The values of the relative error $\delta_{i}(\%)$ for the object with two inclusions

\begin{tabular}{|c|c|c|c|c|c|c|}
\hline \multirow{2}{*}{$k$} & \multicolumn{3}{|c|}{$y z-$ plane } & \multicolumn{3}{c|}{$x y-$ plane } \\
\cline { 2 - 7 } & $\delta_{x}(\%)$ & $\delta_{y}(\%)$ & $\delta_{z}(\%)$ & $\delta_{x}(\%)$ & $\delta_{y}(\%)$ & $\delta_{z}(\%)$ \\
\hline 2 & 3.350 & 3.250 & 5.200 & 43.453 & 1.268 & 25.574 \\
\hline 3 & 2.160 & 1.780 & 2.458 & 8.658 & 0.448 & 17.084 \\
\hline 4 & 1.678 & 0.986 & 1.745 & 3.456 & 0.306 & 3.600 \\
\hline 5 & $\mathbf{0 . 8 4 5}$ & $\mathbf{0 . 4 5 0}$ & $\mathbf{0 . 9 4 2}$ & 1.800 & 0.196 & 1.124 \\
\hline 6 & - & - & - & $\mathbf{0 . 8 2 5}$ & $\mathbf{0 . 1 1 3}$ & $\mathbf{0 . 5 3 6}$ \\
\hline
\end{tabular}

Another case takes into account the object with one inclusion of geometrical dimensions $\Delta x=\Delta y=\Delta z=2 \mathrm{~cm}$ in $x, y$ and $z$ axis. The conductivities of the object and the inclusion are equal to $0.15 \mathrm{~S} / \mathrm{m}$ and $0.01 \mathrm{~S} / \mathrm{m}$, respectively.

The calculations have been made for two different positions of the inclusion in the $x$-direction. Table 4 and 5 show the results for the object with inclusion located shallowly and deeply, respectively.

Table 4. The values of the relative error $\delta_{j}(\%)$ for the object with the inclusion positioned shallowly (inclusion's position: $x_{1}=1 \mathrm{~cm}, x_{2}=3 \mathrm{~cm}$ )

\begin{tabular}{|c|c|c|c|c|c|c|}
\hline \multirow{2}{*}{$k$} & \multicolumn{3}{|c|}{$y z-$ plane } & \multicolumn{3}{c|}{$x y-$ plane } \\
\cline { 2 - 7 } & $\delta_{x}(\%)$ & $\delta_{y}(\%)$ & $\delta_{z}(\%)$ & $\delta_{x}(\%)$ & $\delta_{y}(\%)$ & $\delta_{z}(\%)$ \\
\hline 2 & 3.350 & 2.800 & 3.695 & 16.087 & 2.100 & 3.812 \\
\hline 3 & 1.756 & 1.395 & 1.934 & 6.950 & 1.200 & 2.032 \\
\hline 4 & 0.912 & 0.698 & 1.125 & 3.674 & 0.765 & 1.125 \\
\hline 5 & $\mathbf{0 . 4 8 5}$ & $\mathbf{0 . 3 5 6}$ & $\mathbf{0 . 5 8 7}$ & 1.954 & 0.420 & 0.683 \\
\hline 6 & - & - & - & $\mathbf{0 . 8 3 5}$ & $\mathbf{0 . 2 1 6}$ & $\mathbf{0 . 3 3 6}$ \\
\hline
\end{tabular}

Table 5. The values of the relative error $\delta_{j}(\%)$ for the object with the inclusion positioned deeply (inclusion's position: $x_{1}=7 \mathrm{~cm}, x_{2}=9 \mathrm{~cm}$ )

\begin{tabular}{|c|c|c|c|c|c|c|}
\hline \multirow{2}{*}{$k$} & \multicolumn{3}{|c|}{$y z-$ plane } & \multicolumn{3}{c|}{$x y-$ plane } \\
\cline { 2 - 7 } & $\delta_{x}(\%)$ & $\delta_{y}(\%)$ & $\delta_{z}(\%)$ & $\delta_{x}(\%)$ & $\delta_{y}(\%)$ & $\delta_{z}(\%)$ \\
\hline 2 & 2.556 & 1.400 & 4.160 & 13.835 & 0.165 & 3.260 \\
\hline 3 & 1.345 & 0.480 & 2.113 & 6.320 & 0.093 & 1.980 \\
\hline 4 & 0.840 & 0.300 & 1.234 & 3.125 & 0.051 & 0.996 \\
\hline 5 & $\mathbf{0 . 4 3 0}$ & $\mathbf{0 . 1 7 5}$ & $\mathbf{0 . 7 7 0}$ & 1.456 & 0.027 & 0.443 \\
\hline 6 & - & - & - & $\mathbf{0 . 7 5 6}$ & $\mathbf{0 . 0 1 4}$ & $\mathbf{0 . 2 4 7}$ \\
\hline
\end{tabular}

In the next simulation the object with small inclusion $(\Delta x=\Delta y$ $=\Delta z=1 \mathrm{~cm}$ ) has been analyzed. The electrical conductivity of the object and the inclusion are the same as in the previous models. Table 6 presents results of calculations.

Table 6. The values of the relative error $\delta_{j}(\%)$ for the object with small inclusion

\begin{tabular}{|c|c|c|c|c|c|c|}
\hline \multirow{2}{*}{$k$} & \multicolumn{3}{|c|}{$y z-$ plane } & \multicolumn{3}{c|}{$x y-$ plane } \\
\cline { 2 - 7 } & $\delta_{x}(\%)$ & $\delta_{y}(\%)$ & $\delta_{z}(\%)$ & $\delta_{x}(\%)$ & $\delta_{y}(\%)$ & $\delta_{z}(\%)$ \\
\hline 2 & 3.020 & 4.770 & 5.397 & 10.823 & 1.056 & 5.07 \\
\hline 3 & 1.658 & 2.350 & 2.956 & 5.687 & 0.624 & 2.634 \\
\hline 4 & 0.865 & 1.100 & 1.750 & 2.346 & 1.562 & 1.551 \\
\hline 5 & 0.468 & 0.690 & 1.054 & 1.589 & 0.678 & 0.767 \\
\hline 6 & $\mathbf{0 . 2 5 6}$ & $\mathbf{0 . 3 4 5}$ & $\mathbf{0 . 5 2 4}$ & $\mathbf{0 . 7 5 3}$ & $\mathbf{0 . 2 4 5}$ & $\mathbf{0 . 3 6 8}$ \\
\hline
\end{tabular}

The results for model with lower conductivity inclusion $(\sigma=0.01 \mathrm{~S} / \mathrm{m})$ of complex shape has been presented in Table 7 . The shape of the inclusion has been show in Fig. 4. The largest dimensions of the inclusion are $2 \mathrm{~cm} \times 3.5 \mathrm{~cm} \times 3.5 \mathrm{~cm}$ and the smallest $-0.5 \mathrm{~cm} \times 1 \mathrm{~cm} \times 0.5 \mathrm{~cm}$.

Table 7. The values of the relative error $\delta_{j}(\%)$ for the object with large inclusion of complex shape $(\sigma=0.01 \mathrm{~S} / \mathrm{m})$

\begin{tabular}{|c|c|c|c|c|c|c|}
\hline \multirow{2}{*}{$k$} & \multicolumn{3}{|c|}{$y z-$ plane } & \multicolumn{3}{c|}{$x y-$ plane } \\
\cline { 2 - 7 } & $\delta_{x}(\%)$ & $\delta_{y}(\%)$ & $\delta_{z}(\%)$ & $\delta_{x}(\%)$ & $\delta_{y}(\%)$ & $\delta_{z}(\%)$ \\
\hline 2 & 2.550 & 1.330 & 4.875 & 15.440 & 1.890 & 3.682 \\
\hline 3 & 1.325 & 0.720 & 2.525 & 7.735 & 0.990 & 1.845 \\
\hline 4 & 0.670 & 0.398 & 1.320 & 4.098 & 0.525 & 0.944 \\
\hline 5 & $\mathbf{0 . 3 6 0}$ & $\mathbf{0 . 1 9 8}$ & $\mathbf{0 . 7 5 6}$ & 2.078 & 0.298 & 0.524 \\
\hline 6 & - & - & - & $\mathbf{0 . 9 9 8}$ & $\mathbf{0 . 1 2 5}$ & $\mathbf{0 . 2 2 5}$ \\
\hline
\end{tabular}


In the following simulations numerical analysis has been performed for models with higher conductivity inclusions $(\sigma=0.75 \mathrm{~S} / \mathrm{m})$. The geometrical dimensions of the inclusion are $\Delta x=\Delta y=\Delta z=2 \mathrm{~cm}$ and the inclusion's location in the $x$-direction is: $x_{1}=1 \mathrm{~cm}$ ("shallow" case) and $x_{2}=3 \mathrm{~cm}$ ("deep" case). Table 8 shows calculated values of the relative error $\delta_{j}$.

Table 8 . The values of the relative error $\delta_{j}(\%)$ for the object with the inclusion, which is located shallowly in the object

\begin{tabular}{|c|c|c|c|c|c|c|}
\hline \multirow{2}{*}{$k$} & \multicolumn{3}{|c|}{$y z-$ plane } & \multicolumn{3}{c|}{$x y$ - plane } \\
\cline { 2 - 7 } & $\delta_{x}(\%)$ & $\delta_{y}(\%)$ & $\delta_{z}(\%)$ & $\delta_{x}(\%)$ & $\delta_{y}(\%)$ & $\delta_{z}(\%)$ \\
\hline 2 & 2.221 & 0.614 & 3.900 & 10.110 & 3.561 & 3.927 \\
\hline 3 & 1.167 & 0.326 & 2.050 & 5.153 & 1.985 & 2.020 \\
\hline 4 & 0.734 & 0.190 & 1.190 & 2.738 & 1.010 & 1.126 \\
\hline 5 & $\mathbf{0 . 3 8 5}$ & $\mathbf{0 . 0 9 8}$ & $\mathbf{0 . 4 3 5}$ & 1.423 & 0.573 & 0.714 \\
\hline 6 & - & - & - & $\mathbf{0 . 6 3 0}$ & $\mathbf{0 . 3 2 6}$ & $\mathbf{0 . 3 6 3}$ \\
\hline
\end{tabular}

In Table 9 the results for the inclusion which is located deeply $\left(x_{1}=7 \mathrm{~cm}\right.$ and $\left.x_{2}=9 \mathrm{~cm}\right)$ have been shown.

Table 9. The values of the relative error $\delta_{j}(\%)$ for the object with the inclusion, which is located deeply in the object

\begin{tabular}{|c|c|c|c|c|c|c|}
\hline \multirow{2}{*}{$k$} & \multicolumn{3}{|c|}{$y z-$ plane } & \multicolumn{3}{c|}{$x y-$ plane } \\
\cline { 2 - 7 } & $\delta_{x}(\%)$ & $\delta_{y}(\%)$ & $\delta_{z}(\%)$ & $\delta_{x}(\%)$ & $\delta_{y}(\%)$ & $\delta_{z}(\%)$ \\
\hline 2 & 2.527 & 2.044 & 3.975 & 13.041 & 4.460 & 3.227 \\
\hline 3 & 1.756 & 1.120 & 2.056 & 7.145 & 2.991 & 1.930 \\
\hline 4 & 0.986 & 0.756 & 1.231 & 3.678 & 1.562 & 1.000 \\
\hline 5 & $\mathbf{0 . 5 1 4}$ & $\mathbf{0 . 4 5 0}$ & $\mathbf{0 . 7 8 6}$ & 1.900 & 0.678 & 0.624 \\
\hline 6 & - & - & - & $\mathbf{0 . 9 8 0}$ & $\mathbf{0 . 3 3 4}$ & $\mathbf{0 . 3 2 8}$ \\
\hline
\end{tabular}

Next, the model with small inclusion (of size $1 \mathrm{~cm} \times 1 \mathrm{~cm} \times$ $1 \mathrm{~cm}$ in $x, y$ and $z$ axis, respectively) has been examined. Table 10 shows relevant results.

Table 10. The values of the relative error $\delta_{j}(\%)$ for the object with small inclusion $(\sigma=0.75 \mathrm{~S} / \mathrm{m})$

\begin{tabular}{|c|c|c|c|c|c|c|}
\hline \multirow{2}{*}{$k$} & \multicolumn{3}{|c|}{$y z-$ plane } & \multicolumn{3}{c|}{$x y-$ plane } \\
\cline { 2 - 7 } & $\delta_{x}(\%)$ & $\delta_{y}(\%)$ & $\delta_{z}(\%)$ & $\delta_{x}(\%)$ & $\delta_{y}(\%)$ & $\delta_{z}(\%)$ \\
\hline 2 & 3.056 & 0.871 & 5.200 & 12.052 & 0.782 & 4.676 \\
\hline 3 & 1.557 & 0.432 & 2.789 & 3.930 & 0.445 & 2.630 \\
\hline 4 & 0.889 & 0.265 & 1.398 & 1.811 & 0.286 & 1.765 \\
\hline 5 & $\mathbf{0 . 4 4 6}$ & $\mathbf{0 . 1 5 0}$ & $\mathbf{0 . 7 6 5}$ & 1.051 & 0.156 & 0.966 \\
\hline 6 & - & - & - & $\mathbf{0 . 5 8 6}$ & $\mathbf{0 . 0 9 8}$ & $\mathbf{0 . 4 4 7}$ \\
\hline
\end{tabular}

The last considered case takes into account the object with inclusion of complex shape (Fig. 5). Table 11 presents calculated values of the relative error $\delta_{j}$.

Table 11. The values of the relative error $\delta_{j}(\%)$ for the object with large inclusion of complex shape $(\sigma=0.75 \mathrm{~S} / \mathrm{m})$

\begin{tabular}{|c|c|c|c|c|c|c|}
\hline \multirow{2}{*}{$k$} & \multicolumn{3}{|c|}{$y z-$ plane } & \multicolumn{3}{c|}{$x y-$ plane } \\
\cline { 2 - 7 } & $\delta_{x}(\%)$ & $\delta_{y}(\%)$ & $\delta_{z}(\%)$ & $\delta_{x}(\%)$ & $\delta_{y}(\%)$ & $\delta_{z}(\%)$ \\
\hline 2 & 2.900 & 2.854 & 5.286 & 13.700 & 6.750 & 5.800 \\
\hline 3 & 2.000 & 1.754 & 2.780 & 10.098 & 2.327 & 3.182 \\
\hline 4 & 0.985 & 0.750 & 1.500 & 4.400 & 0.530 & 1.600 \\
\hline 5 & $\mathbf{0 . 5 1 5}$ & $\mathbf{0 . 3 8 7}$ & $\mathbf{0 . 9 8 5}$ & 1.980 & 0.190 & 0.768 \\
\hline 6 & - & - & - & $\mathbf{0 . 9 5 0}$ & $\mathbf{0 . 0 7 5}$ & $\mathbf{0 . 3 3 8}$ \\
\hline
\end{tabular}

\section{Conclusions}

In this paper the degree of the discretization level for the proper determination of the secondary magnetic field map in the Magnetic Induction Tomography has been studied. Two different measurement planes have been chosen as reference grids and many various object-inclusions setups have been considered. In all cases the relative errors $\delta(\%)$ and maximal elements' volumes have been determined.

As expected, the error analysis shows that the object's discretization level has significant impact on the accuracy of the secondary magnetic field calculations. In general it can be concluded that for proper magnetic field determining the object must be divided into almost 120 millions rectangular prisms (it corresponds to the individual rectangular prism volume value equal to $0.244 \mathrm{~mm}^{3}$ ) and almost 1 mld (corresponds to the individual rectangular prism volume value equal to $0.03 \mathrm{~mm}^{3}$ ), for $y z$ and $x y$ measurement planes, respectively. In the case of small inclusion of conductivity equal to $0.01 \mathrm{~S} / \mathrm{m}$ the object should be divided into elements with individual rectangular prism volume equal to $0.03 \mathrm{~mm}^{3}$.

In most cases the smallest values of relative errors have been achieved for $y$-magnetic field component. The lowest values of $\delta_{y}$ equal to $0.098 \%$ and $0.014 \%$ have been attained for $y z-$ and $x y$ - planes, respectively.

It can be also stated, that the values of $\delta(\%)$ depend on the locations, sizes, shapes and conductivities of the inclusions. For the inclusion of electrical conductivity higher than the object, which is located deeper greater values of relative errors have been obtained than for the inclusion situated shallowly. It's apparently observed for $y$ component of the magnetic flux density vector (see table 8 and table 9). Therefore, in future work, we plan use more discretization levels in image reconstruction techniques to improve detection of deeply located hematoma and tumors.

\section{References}

[1] Gratkowski S., Pałka R., Baniukiewicz P., Komorowski M., Stawicki K.: Numerical simulation of eddy current problems in magnetic induction tomography. Przegląd Elektrotechniczny 11/2007, 219-222.

[2] Gratkowski S., Pichon L., Gajan H.: Asymptotic boundary conditions for open boundaries of axisymmetric magnetostatic finite-element models. IEEE Transactions on Magnetics 38/2002, 469-472.

[3] Ma L., Wei H.-Y., Soleimani M.: Pipelines inspection using magnetic induction tomography based on a narrowband pass filtering method. Progress In Electromagnetics Research M 23/2012, 65-78.

[4] Morris A.: Image reconstruction in magnetic induction tomography, ProQuest, 2004.

[5] Muahammad S., Zaulkarnay Z., Balkhis J., Ruzairi A. et all: Magnetic induction tomography - A brief review. Jurnal Teknologi 73/2015, 91-95.

[6] Stawicki K., Szuflitowska B., Ziolkowski M.: Recent simulation results of the magnetic induction. Archives of Electrical Engineering 65/2016, 327-336.

[7] Ziolkowski M., Gratkowski S., Palka R.: Solution of three dimensional inverse problem of magnetic induction tomography using Tikhonov regularization method. International Journal of Applied Electromagnetics and Mechanics 30/2009, 245-253.

[8] www.itis.ethz.ch/virtual-population/tissue-properties/database/dielectricproperties/ (available 07.2015)

\begin{abstract}
M.Sc. Beata Szuflitowska
e-mail: beata.szuflitowska@zut.edu.pl

Beata Szuflitowska graduated from the University of Szczecin and Pomeranian Medical University in Szczecin. Currently she is Ph.D. student at West Pomeranian University of Technology, Szczecin. Research topics: electromagnetic field, nondestructive testing, brain-computer interface and model predictive control.
\end{abstract}

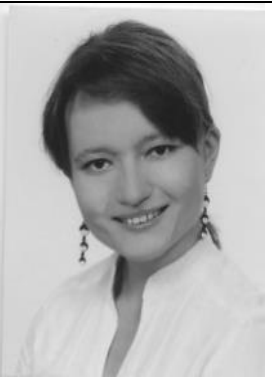

D.Sc. Ph.D. Marcin Ziolkowski from the Szczecin University of Technology, e-mail: marcin.ziolkowski@zut.edu.pl

Marcin Ziolkowski received the M.Sc., Ph.D. and D.Sc. (habilitation) degrees in Electrical Engineering Szczecin, Poland and West Pomeranian University of Technology, Szczecin, Poland in 2001, 2006 and 2012 , respectively. Since 2008, he has been working with the Department of Electrical and Computer Engineering, Electrical Engineering Faculty, West Pomeranian University of Technology, Szczecin, Poland. His main research interests include numerical calculations and visualization of EM fields, inverse problems, electromagnetic field shielding and nondestructive testing of materials.

Ph.D. Krzysztof Stawicki

e-mail: krzysztof.stawicki@zut.edu.pl

Krzysztof Stawicki graduated from the Faculty of Electrical Engineering, Szczecin University of Technology (2000). He obtained his Ph.D. degree in Electrical Engineering from the Szczecin University of Technology in 2005. His research and education activities are within the area of electromagnetic field theory and applications, in particular non-destructive

testing and numerical techniques.
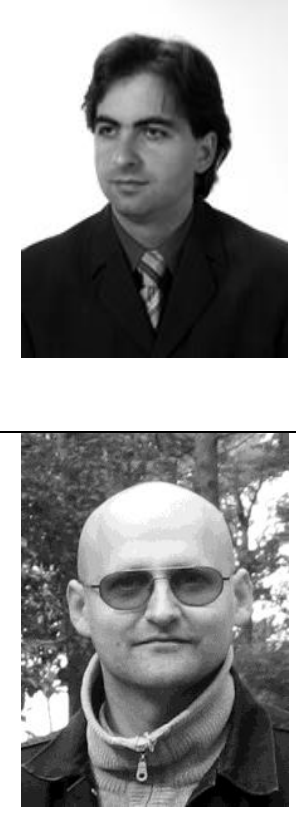

otrzymano/received: 15.06 .2016 